\title{
The Game of Thinking. Interactions Between Children and Robots in Educational Environments
}

\author{
Luisa Zecca
}

\begin{abstract}
Educational robotics (ER) fits into a constructivist perspective that aims to overcome the dichotomy between researchers and practitioners through collaborative research. This sparks reflection on how to develop professional training for teachers. The laboratory is the privileged setting of ER activities. It is an educational space for training and research alike, and is suitable for learning to do, whereby children can handle robots and develop scientific skills. The Laboratory of Robotics for the Cognitive and Social Sciences of the University of Milano-Bicocca, directed by Professor Edoardo Datteri, conducted a series of activities within this framework. Using an ethnographic approach informed by grounded theory, where the teacher acts as a mediator rather than an instructor, the project included: labs in primary schools involving a Lego Mindstorms robot assembled as a small vehicle; labs in lower secondary schools to study the different approaches of teachers; a robot programming activity with preschool children at "Bambini Bicocca." These research activities give children the opportunity to develop scientific and thinking skills, and show that ER can engage students in metacognitive reflection. Moreover, thanks to a well thoughtout laboratory approach, robotics can cut across several educational skills, such as learning to learn, acting autonomously, solving problems. An in-depth study of the interactions between adults, children and robots also plays an important role in advancing the research with new knowledge for action: it sheds light on the problemsolving strategies of students and the behaviors of children and teachers.
\end{abstract}

Keywords Laboratory $\cdot$ Collaborative research $\cdot$ Educational robotics $\cdot$ Science education $\cdot$ Thinking Skills

\footnotetext{
L. Zecca $(\varangle)$

University of Milano-Bicocca, 20126 Milan, Italy

e-mail: luisa.zecca@unimib.it 


\section{Laboratory Approach and Educational Robotics}

The laboratory is a specialized educational space suitable for producing critical, reflective and imaginative thinking, which is shown to be an effective theoretical and experiential device for acquiring those skills that Dewey called learning to think and learning to do [7]. Indeed, in the theory-practice nexus, different educational objectives are linked and procedural knowledge is transformed into smart expertise. This occurs through the reformulation of problems, the search for new solutions, and verification and review of thinking processes. Operating climate and collaboration are distinctive features of lab methodology and configure an educational setting of mutual help, where dialog and discussion permeate the work community [10].

Collaborative research is one of the main models of participatory research, which aims to look beyond the dichotomy between researchers and practitioners, in order to foster a dialog between theoretical knowledge and pragmatic knowledge for shared research. The aim is not merely to identify the practical implications for schools of new academic knowledge. Indeed, collaborative research also aims to spark reflection on how professional training for teachers can be developed [1,6]. Thus, the laboratory is an educational space characterized by research and training alike. It is a privileged setting where new knowledge can be developed and, at the same time, there can be reflection on the activities and experiences, in a continuous process of destructuring and restructuring.

Educational robotics fits into this constructivist perspective, because it involves a form of electronics that can enhance learning through new ways of constructing meaning. Educational robots have come a long way since Papert, especially thanks to the approach of learning by doing through multi-level interaction. First, they are relatively safe and children can handle and experiment with them themselves, without the need for close teacher supervision. Also, although robotic behaviors depend in part on environmental and internal factors, educational robots are relatively predictable. This makes analyzing robots less frustrating than studying animals or plants. Their use helps children to develop research skills, such as observation, explanatory hypothesis formulation, hypothesis testing, and review of hypotheses in light of the results observed. Furthermore, they can encourage them to reflect metacognitively on the fundamentals of scientific research methodology. Indeed, as they carry out these activities, children have to think actively about what they are doing. This causes them to adopt a metacognitive perspective involving epistemological and methodological reflection [5].

The "Riccardo Massa" Department of Human Sciences for Education of the University of Milano-Bicocca has pursued these goals for years in a research project that aims to observe the development of scientific skills in children and devise methodological guidelines to plan and assess ER activities. 


\section{Towards the Game of Thinking in Primary Schools}

Since 2011, our department has held several ER laboratories in primary schools in Milan, involving a Lego Mindstorms robot assembled as a small vehicle, programmed in advance with the NXT-G software to function as a Braitenberg-like vehicle. During these activities, instead of programming a robot, children have to find out how the robot has been programmed. It is in this that these learning activities differ from conventional approaches to educational robotics: instead of identifying sequences of motor commands, they are asked to explain the robot's behavior. To encourage deep learning in various scientific disciplines and develop abstract thinking and problemsolving skills, children are asked to describe what the robot was doing and to explain why it was doing it. They are free to interact with the robot, to get close to it and to put their hands near the sensors [2-4].

These robotics activities were labeled the Game of Science by the first group of eight-year-olds to do this activity with us. It involves studying the robot's behavior in ways similar to how ethologists study living animals, which is why it can be defined as "roboethology." We audio-recorded the verbal interactions among children and between teachers and children and adopted an ethnographic approach informed by grounded theory to identify and categorize the scientific and abstract reasoning skills displayed by children. The teacher acts as a mediator rather than as an instructor: he or she should avoid answering the children's questions or correcting their views, and instead should reformulate the questions raised by the children and ask them for explanations and justifications. This dialogical approach stimulates independent reasoning in children and encourages them to experiment.

\subsection{Considerations on Experimental Adequacy and Refining the Setting}

Among the other hypotheses formulated by children at one of the sessions was the idea that the robot was moving randomly. To test this theory, the children devised an experiment. It consisted of making a door in an experimental arena with several obstacles, and seeing whether the robot was able to go through it to leave the arena (see Fig. 1). The children reasoned that a randomly moving robot would collide with the obstacles, therefore it would fail the objective of finding the way out.

However, as we can see from the exchange below, formulating an experiment means evaluating the suitability of the experiment and, potentially, refining it:

$\mathrm{T}[$ eacher]: $\mathrm{C} 1$, should the door be wide or narrow?

C[hild]1: Narrow...

T: Like this?

C1: No...

T: Should it be narrower? 
Fig. 1 The experimental arena with a door and some obstacles. Is the robot moving randomly?

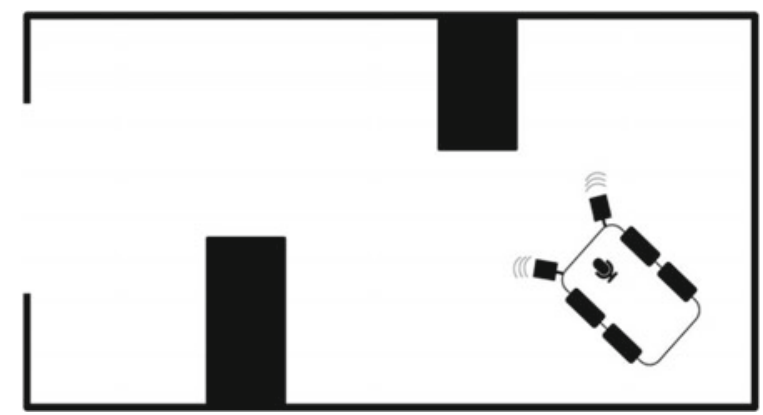

$\mathrm{C} 1$ : We need to add a brick [to make the door narrower].

C2: Yes, because if you put the robot there, it will go out straightaway.

The point is that if the door is too wide the robot may leave the arena by chance. Therefore, an arena with a wide door is a bad experimental setting for testing whether or not the robot moves randomly. For this reason, children suggest refining the experimental setting in order to rule out alternative explanations.

\subsection{Drawing Theoretical Conclusions and Identifying Alternative Explanations}

At this point, one child imagines that if the robot is not moving randomly, it will go out. In short, he is predicting what the robot will do, if a given theory is true. But not everyone agrees, as we can see from the excerpt here:

T: If it goes outside the arena, that means it is not moving randomly. Do you all agree?

C: I don't agree. If it leaves immediately, it isn't moving randomly. But if it hits a box and then goes out, then it's moving randomly.

The child identifies two possible experimental results and he concludes that, if the robot exits after bumping into obstacles, it means it cannot see and therefore is moving randomly, even if it is able to exit. He is showing the ability to draw theoretical conclusions from possible experimental results. But we also notice that different interpretations can be made from the same behavior, as is evident in the following excerpt:

$\mathrm{C}:[\ldots]$ but maybe the robot hits the obstacles because it's got a map inside its mind, and it can't see the obstacles.

Here the child identifies a potential alternative (as yet unseen) explanation for the robot's behavior. So, we can conclude that the door experiment is not adequate for deciding whether or not the robot's movements are random.

Children were asked to observe a target system, describe it, identify the phenomena, propose explanatory hypotheses, make predictions, design experiments, 
compare the experimental results with their predictions and revise their hypotheses in line with the results [11]. Thus, educational robots appear to be particularly suitable tools for organizing scientific laboratories in schools, where we can also examine, among other things, the different direction styles of teachers, which have a strong impact on the knowledge environment.

\section{Robotic Labs and Different ER Approaches of Teachers}

In the 2013/2014 academic year, we conducted a case study in three lower secondary schools that had joined Amicorobot, a network of schools that promotes research, training, and experimentation in ER. These three schools held robotics labs for 20 years. This enabled us to study in-depth the different ER direction styles of teachers leading the labs, especially related to the verbal interactions between teachers and the class as a group. The analysis of their interactions was compared with the objectives declared by the teachers themselves and with the organizational environment, with the idea that there is strong reciprocity between objectives, interactions and organization [9].

During this case study, the teachers were the first to want to start a metacognitive analysis of their practices. With the aid of video recordings, we identified three different ER approaches among the teachers:

1. content-based learning, which views the laboratory as a space where the acquisition of knowledge can be tested along with the capacity to apply it;

2. cooperative learning, which aims to solve problems creatively and works toward developing team-building skills;

3. problem-based learning, which stimulates dialog between equals and an autonomous and shared design, as well as testing the skills acquired during previous educational robotics laboratories.

In addition to the construction of educational robots, understanding different lab approaches helps advance educational research with new knowledge for practice. This would be helpful to other teachers taking similar paths. Specifically, studying the interaction between children, adults and robots in order to understand problemsolving attitudes could help structure targeted education interventions, as in the following example.

\subsection{Programming a Robot with Preschool Children at "Bambini Bicocca" Infant School}

In 2018, our department held a robot programming workshop at the "Bambini Bicocca" Infant School. We conducted seven separate sessions lasting around $40 \mathrm{~min}$ each, with the participation of seven children aged between 4 and 5. Educational 
robots are a useful focus of scientific inquiry, even for preschool children. Cubetto, a robot produced in 2013, is particularly suitable for children up to the age of six. After explaining the operating procedures with the robot, the teacher-researcher posed some programming problems to children. The activities were recorded using three video cameras and the data collected were examined in a specific software program. The main purpose was to examine the interaction between children, adults and robots, to explain the problems and solving strategies faced by the children and to understand what types of tutoring the teachers implemented [8].

The children faced various problems, such as:

1. issues with defining the objectives: children were given the freedom to suggest how to structure the objective; all the problems that arose originated from their spontaneous suggestions;

2. programming problems, related to building the code;

3. problems related to Cubetto's interlocking blocks;

4. verification issues, that is, all the problems arising from solving the objective, from building the code to checking its effectiveness, once it was built;

5. directional issues related to how the robot moved;

6. issues with defining all the movements that Cubetto should make to achieve the assigned goal (these are related to programming issues);

7. issues with detecting errors: all the problems that enable children to locate the errors they have made.

The children employed strategies that were specific to each problem they were confronted with, such as:

1. observation and intuition, whereby they figured out what to do to achieve an objective by looking at the problem;

2. decomposition of a problem or an objective into several parts;

3. mental simulation, i.e., mental representation of the movements the robot should make to achieve its objective;

4. body simulation, where the child represents the itinerary physically with his own body;

5. strategy of direct verification during programming;

6. verbal simulation, meaning, all the heuristic procedures guided by a verbal explanation of what movements the robot should make;

7. indifference to problems, which enables children to choose other strategies to reach the objective;

8. distress call and listening strategies;

9. trial and error.

As mentioned above, it may be useful to have an understanding of what children see as problems and their strategies for addressing them, to enable teachers to structure educational interventions. First, this classification can predict the behavior of children involved in robotics activities. Second, it can be used as a guide for observing 
their behavior. Lastly, identifying problems and strategies can provide effective support tool for teachers or experts who want to work in the field of educational robotics.

\section{Conclusions}

In recent years, our RobotiCSS Lab has conducted other robotics activities in schools - in addition to the research already mentioned-involving other types of robots, including Lego WeDo 2.0 and Blue-Bot. These activities provide children with an opportunity to develop science skills and competences and a stimulus to reflect metacognitively on the fundamentals of scientific research methodology. These experiences also showed that robotics extends beyond the didactic, through technology laboratories and active methods, to encompass cross-cutting educational features. A well-thought-out laboratory approach helps children to learn to learn, plan, communicate and collaborate, act independently and responsibly, solve problems, identify connections and interpret information.

It is a fact that the educational use of robots stimulates productive, creative and divergent thinking and is useful for understanding how students learn. However, in order to achieve these goals and continue to make progress, we must not forget that it is extremely important to strengthen the professionalism of teachers, through research-training and participatory action research.

\section{References}

1. Asquini, G. (ed.): La Ricerca-Formazione. Temi, esperienze e prospettive. Franco Angeli, Milan (2018)

2. Datteri, E., Zecca, L.: Il "gioco dello scienziato": un robot per imparare a spiegare. Mondo Digitale 14(58), 978-988 (2015)

3. Datteri, E., Zecca, L.: The game of science: an experiment in synthetic roboethology with primary school children. IEEE Robot. Autom. Mag. 23(2), 24-29 (2016)

4. Datteri, E., Bozzi, G., Zecca, L.: Il "Gioco dello Scienziato" per l'apprendimento del metodo scientifico nella scuola primaria. TD Tecnologie Didattiche 23(3), 172-175 (2015)

5. Datteri, E., Zecca, L., Laudisa, F., Castiglioni, M.: Learning to explain: the role of educational robots in science education. Themes Sci. Technol. Educ. 6(1), 29-38 (2013)

6. Desgagné, S.: Le concept de recherche collaborative: l'idée d'un rapprochement entre chercheurs universitaires et praticiens enseignants. Revue des sciences de l'éducation 23(2), 371-393 (1997)

7. Dewey, J.: Democracy and Education: An Introduction to the Philosophy of Education. Macmillan, New York (1916)

8. Scannapieco, S.: A robot in kindergarten: problems and strategies for problem solving, Thesis in Educational Sciences, University of Milano-Bicocca, Supervisor: Prof. Edoardo Datteri, Co-Supervisor: Prof. Luisa Zecca (2019)

9. Zecca, L.: Conversazioni con i bambini e stili educativi. In: Demetrio, D., Zecca, L. (eds.) Appunti per una ricerca sugli stili educativi, pp. 145-168. CUEM, Milan (2000) 
10. Zecca, L.: Didattica laboratoriale e formazione Bambini e insegnanti in ricerca. Franco Angeli, Milan (2016)

11. Zecca, L.: I pensieri del fare. Verso una didattica metariflessiva. Junior, Parma (2012)

Open Access This chapter is licensed under the terms of the Creative Commons Attribution 4.0 International License (http://creativecommons.org/licenses/by/4.0/), which permits use, sharing, adaptation, distribution and reproduction in any medium or format, as long as you give appropriate credit to the original author(s) and the source, provide a link to the Creative Commons license and indicate if changes were made.

The images or other third party material in this chapter are included in the chapter's Creative Commons license, unless indicated otherwise in a credit line to the material. If material is not included in the chapter's Creative Commons license and your intended use is not permitted by statutory regulation or exceeds the permitted use, you will need to obtain permission directly from the copyright holder.

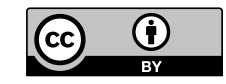

